\title{
Meiotic inhibition of bovine oocytes in medium supplemented with a serum replacer and hormones: effects on meiosis progression and developmental capacity
}

\author{
Letícia Siqueira Sá Barretto ${ }^{2}$, Viviane Sgobbi Dias Caiado Castro ${ }^{2}$, Joaquim Mansano Garcia ${ }^{2}$ \\ and Gisele Zoccal Mingoti ${ }^{1}$ \\ School of Veterinary Medicine, Department of Animal Health, UNESP, Araçatuba; and School of Agricultural and Veterinary \\ Sciences, Department of Animal Reproduction, UNESP, Jaboticabal, SP, Brazil
}

Date submitted: 26.08.2009. Date accepted: 15.02.2010

\section{Summary}

Aiming to improve the developmental competence of bovine oocytes during meiotic block, this study evaluated the effects of a serum replacer (Knockout $S R^{\circledR}$ ) and hormones (gonadotropins and estradiol) supplementation of prematuration medium (TCM119 with $0.5 \mathrm{mM}$ IBMX [IBMX group] or $25 \mu \mathrm{M}$ roscovitine [ROSC group]) on the kinetics of oocyte nuclear maturation and embryo development. Most IBMX and ROSC oocytes prematured for $8 \mathrm{~h}$ culture remained in the GV stage $(70.3 \%$ and $73.1 \%$, respectively; $p>0.05$ ) similar to Control $8 \mathrm{~h}(63.5 \%)$ and to control immature oocytes (Control $0 \mathrm{~h}$, 92.5\%). After prematuration for $16 \mathrm{~h}$, no oocytes remained in the GV stage at similar rates to those recently aspirated $(p<0.05)$; GV rates in ROSC (32.4\%) were higher $(p<0.05)$ than in the Control $16 \mathrm{~h}$ group (8.6\%), but similar $(p>0.05)$ to IBMX (9.7\%). After in vitro maturation (IMV) for $24 \mathrm{~h}$, metaphase II (MII) rates for oocytes prematured during $8 \mathrm{~h}$ were similar $(p>0.05)$ between control and treatments (65.0-71.7\%). Similarly, MII rates oocytes prematured during $16 \mathrm{~h}$ were similar $(p>0.05)$ between all groups (45.9-60.4\%). Cleavage rates (67.8-78.2\%), embryonic development in day-7 (25.0-35.6\%) and hatching rates in day-8 (2.5-11.3\%) oocytes blocked during $8 \mathrm{~h}$ were similar for all groups $(p>0.05)$. Results indicate that addition of Knockout $\mathrm{SR}^{\circledR}$ and hormones to meiotic block culture with IBMX and roscovitine negatively affected meiotic arrest, but did not impair oocyte nuclear maturation and acquisition of developmental competence.

Keywords: Cattle, IBMX, Knockout serum replacer, In vitro maturation, Meiotic arrest, Roscovitine

\section{Introduction}

Oocyte differentiation is a very long process starting during fetal life and culminating in preovulatory follicle as the oocyte reaches its full competence to resume meiosis and successfully accomplish both nuclear and cytoplasmic aspects of maturation (reviewed by Gosden et al., 1997). Meiotically competent

\footnotetext{
${ }^{1}$ All correspondence to: Gisele Zoccal Mingoti. Rua Clóvis Pestana, 793, Department of Animal Health, School of Veterinary Medicine, UNESP, Araçatuba, 16050-680, São Paulo, Brazil. Tel: +55 18 36361357. Fax: +55 1836361352. e-mail: gmingoti@fmva.unesp.br

${ }^{2}$ School of Agricultural and Veterinary Sciences, Department of Animal Reproduction, UNESP, 14884-900, Jaboticabal, SP, Brazil.
}

oocytes aspirated from ovarian follicles and cultured in a suitable culture medium spontaneously reinitiate meiosis, which initiates with the germinal vesicle breakdown (GVBD) and proceeds to metaphase of the second meiotic division (MII). Accompanying nuclear maturation, many cytoplasmic changes occur, such as cortical granule (CG) migration and mitochondria repositioning. Both nuclear and cytoplasmic maturation are considered essential for normal embryo development after fertilization (Yang et al., 1998).

However, the ability of the in vitro matured and fertilized bovine oocytes to develop to the morula/ blastocyst stage is less than that obtained in in vivo produced embryos (Rizos et al., 2002). The decrease in the developmental competence of such oocytes may be due to the insufficient cytoplasmic maturity, which is gradually acquired in vivo during follicular 
growth. During this period, which has been termed oocyte 'capacitation', the oocyte undergoes structural changes that could be related to oocyte competence for development (Hyttel et al., 1997).

Thus, it can be hypothesized that oocytes prematuration in the presence of meiotic inhibitors, a procedure that could more precisely mimic in vivo oocyte capacitation (Ponderato et al., 2001), could give them the opportunity to acquire greater developmental competence (Avery et al., 1998). By using this procedure, the oocyte could undergo the repositioning of organelles and storing of newly synthesized proteins and ribonucleoproteins, which in turns could increase its developmental competence (Rodriguez et al., 2004). Some pharmacological inhibitors utilized for the maintenance of meiotic arrest that have been studied include isobutyl-methylxanthine (IBMX) and roscovitine.

Purine derivatives more specifically directed toward the inhibition of cell cycle regulating cyclin-dependent kinases (CDKs) have been used for preventing cell division and meiotic resumption (Marchal et al., 2001). Roscovitine, a purine known to specifically inhibit M-phase promoting factor (MPF) kinase activity in numerous cell systems, has been successfully used in maintaining cattle oocytes at the germinal vesicle stage without affecting their developmental potential (Mermillod et al., 2000). This drug is a selective cdc2 inhibitor (kinase subunit of MPF complex), which has been reported to arrest cells in late G1 and $\mathrm{G} 2 / \mathrm{M}$ cell cycle transition and inhibit resumption of meiosis (Mermillod et al., 2000). It acts as a competitive inhibitor for ATP and when complexed with cdk2, it binds to the ATP-binding pocket of cdk2.

Cyclic AMP (cAMP) maintains meiotic arrest in GVBD-competent oocytes and helps growing oocytes to acquire competence (Chesnel et al., 1994). IBMX, a phosphodiesterase inhibitor by increasing cAMP (Tsafriri et al., 1996), can maintain bovine cumulusoocyte complexes (COC) in meiotic arrest for a short period (Lonergan et al., 1997). However, as the action of cAMP and its analogues may be modified by the presence of serum, growth factors and hormones added to the culture media (Lohman \& Walter, 1984), synthetic and defined supplement sources of culture media may be used as substitutes. The serum replacer Knockout $S R^{\circledR}$ (SR; BRL) is a protein source used for stem cell culture and whose defined formula is protected by fabricant, but that do not have serum in its composition (Goldsborough et al., 1998).

The objectives of this study were first, to analyze the kinetics of bovine oocyte nuclear maturation following release from meiosis inhibition by IBMX and roscovitine in media supplemented with Knockout
$\mathrm{SR}^{\circledR}$ and hormones; and second, to assess the developmental capacity of such oocytes.

\section{Material and methods}

\section{Reagents, media and culture conditions}

Chemicals were purchased from Sigma Chemical Co. (St. Louis, MO, USA), unless otherwise stated.

Inhibitors were prepared as a stock solution of $5 \mathrm{mM}$ in dimethylsulphoxide (DMSO), aliquoted and stored at $-20^{\circ} \mathrm{C}$ until use. For meiotic block culture, inhibitors were diluted to the appropriate concentration in in vitro maturation (IVM) medium (see below): $25 \mu \mathrm{M}$ roscovitine (Calbiochem, EMD Biosciences Inc.) and $0.5 \mathrm{mM}$ IBMX.

The IVM medium consisted of TCM-199 (Gibco BRL) supplemented with $0.2 \mathrm{mM}$ sodium pyruvate, 25 $\mathrm{mM}$ sodium bicarbonate, $75 \mu \mathrm{g} / \mathrm{ml}$ kanamycin (Gibco BRL), $0.5 \mu \mathrm{g} / \mathrm{ml} \mathrm{FSH}$ (Pluset ${ }^{\circledR}$, Hertape Calier), 100 $\mathrm{IU} / \mathrm{ml} \mathrm{hCG}$ (Profasi ${ }^{\circledR}$, Serono), $1.0 \mu \mathrm{g} / \mathrm{ml}$ estradiol and $10 \%(\mathrm{v} / \mathrm{v})$ Knockout SR ${ }^{\circledR}$ (SR).

In vitro fertilization (IVF) medium consisted of Tyrode's albumin lactate pyruvate (TALP) supplemented with $0.2 \mathrm{mM}$ sodium pyruvate, $6 \mathrm{mg} / \mathrm{ml}$ fatty acidfree BSA, $25 \mathrm{mM}$ sodium bicarbonate, $13 \mathrm{mM}$ sodium lactate, $75 \mu \mathrm{g} / \mathrm{ml}$ kanamycin, $4 \mu \mathrm{l} / \mathrm{ml}$ PHE solution ( $2 \mathrm{mM}$ penicillamine, $1 \mathrm{mM}$ hypotaurine and $250 \mu \mathrm{M}$ epinephrine) and $10 \mu \mathrm{g} / \mathrm{ml}$ heparin.

In vitro culture (IVC) medium was synthetic oviductal fluid (SOF) supplemented with $0.2 \mathrm{mM}$ L-glutamine, $0.34 \mathrm{mM}$ sodium citrate, $2.8 \mathrm{mM}$ myoinositol, 2\% MEM essential amino acid solution, 1\% MEM non-essential amino acid solution, $0.2 \mathrm{mM}$ sodium pyruvate, $75 \mu \mathrm{g} / \mathrm{ml}$ kanamycin, $5 \mathrm{mg} / \mathrm{ml}$ fraction V fatty acid free BSA and $2.5 \%$ FCS.

Cultures (meiosis block, IVM, IVF and IVC) were carried out at $38.5^{\circ} \mathrm{C}$ with maximum humidity and under atmosphere of $5 \% \mathrm{CO}_{2}$ in air.

\section{Oocyte recovery}

Abattoir-derived ovaries were transported to the laboratory in saline solution at $30-35^{\circ} \mathrm{C}$. The follicles (2-8 $\mathrm{mm}$ ) were aspirated using an 18-gauge needle attached to a $20 \mathrm{ml}$ syringe. Oocytes with at least four layers of cumulus cells were selected for the experiments.

\section{Meiosis block (prematuration culture)}

Oocytes where the meiotic block was applied were cultured in vitro in IVM medium supplemented with $10 \% \mathrm{SR}$, hormones and $25 \mu \mathrm{M}$ roscovitine or $0.5 \mathrm{mM}$ IBMX. The culture was performed in $100 \mu \mathrm{l}$ droplets 
(approximately 20 oocytes per droplet) under mineral oil (Dow Corning Co.) during $8 \mathrm{~h}$ or $16 \mathrm{~h}$, according to the experimental approach.

\section{In vitro maturation}

For IVM, oocytes were washed and cultured in IVM medium supplemented with 10\% SR and hormones. The IVM culture was performed in $100 \mu$ droplets (approximately 20 oocytes per droplet) under mineral oil for $24 \mathrm{~h}$ (control group) or for 8,16 and $24 \mathrm{~h}$ (blocked groups).

\section{Assessment of nuclear maturation}

Oocytes were stripped from their cumulus cells by vortexing in phosphate-buffered saline (PBS) with $0.1 \%$ hyaluronidase for $3 \mathrm{~min}$. Denuded oocytes were then stained with $10 \mu \mathrm{g} / \mathrm{ml}$ Hoechst 33342 for $10 \mathrm{~min}$, placed between slide and coverslip and visualized under epifluorescence microscopy (330$385 \mathrm{~nm}$; at $\times 200$ magnification). The oocytes were classified as germinal vesicle stage (GV, immature oocytes), metaphase I (MI), anaphase I (AI), telophase I (TI) or metaphase II (MII, matured oocytes). Oocytes remaining at the GV stage after meiotic block culture were considered to be completely blocked and oocytes in MII after IVM were considered to be fully reversed of the meiotic inhibition. Oocytes reaching MI, AI and TI were considered as intermediate stages (INT).

\section{In vitro fertilization}

Motile spermatozoa were obtained by centrifugation of frozen-thawed spermatozoa on a Percoll (Pharmacia) discontinuous density gradient ( $2 \mathrm{ml}$ of $45 \%$ Percoll over $2 \mathrm{ml}$ of $90 \%$ Percoll) for $30 \mathrm{~min}$ at $900 \mathrm{~g}$ at room temperature. The supernatant was discarded and the spermatozoa were resuspended in IVF medium after being counted on a hemocytometer to obtain a final concentration of $2 \times 10^{6}$ cells $/ \mathrm{ml}$. Oocytes and sperm were co-incubated for $18 \mathrm{~h}$ under the same temperature and atmosphere conditions used for IVM.

\section{In vitro development culture and embryo evaluation}

Following fertilization, the presumptive zygotes were transferred to IVC medium. Zygotes were incubated under mineral oil up to $48 \mathrm{~h}$ for assessment of cleavage rates under stereoscopic microscopy (at $\times 40$ magnification), when 2- and 4-cell embryos were counted. Blastocyst and hatched blastocyst development rates were observed, respectively, at 168 (day 7) and 192 (day 8) hours post insemination (hpi).

\section{Experimental design}

Experiment I: Effects of IBMX or roscovitine diluted in IVM medium supplemented with SR and hormones on effectiveness of meiotic block and meiosis progression after meiotic block of bovine oocytes

Oocytes were blocked for $8 \mathrm{~h}$ (first part of this experiment; $n=412$ in 11 replicates) and for $16 \mathrm{~h}$ (second part of this experiment; $n=236$ in seven replicates) with $0.5 \mathrm{mM}$ IBMX (group IBMX) or $25 \mu \mathrm{M}$ roscovitine (group ROSC) diluted in IVM medium (TCM-199) supplemented with $10 \%$ SR and hormones $(0.5 \mu \mathrm{g} / \mathrm{ml}$ FSH, $100 \mathrm{IU} / \mathrm{ml} \mathrm{hCG}$ and $1.0 \mu \mathrm{g} / \mathrm{ml}$ estradiol). As controls, a group of oocytes was only in vitro matured during $8 \mathrm{~h}(n=203)$ and $16 \mathrm{~h}(n=130)$, respectively, without prior meiotic block. At the end of cultures, all oocytes were assessed for maturation rates. A group of oocytes was fixed after aspiration $(n=89$; Control $0 \mathrm{~h})$.

After meiotic block culture for $8 \mathrm{~h}$ (first part; $n=$ 2543 in 11 replicates) and for $16 \mathrm{~h}$ (second part; $n=$ 2054 in 11 replicates), oocytes were IVM for $24 \mathrm{~h}$. As controls, a group of oocytes was only in vitro matured during $24 \mathrm{~h}$ without prior meiotic block. During IVM, all oocytes were assessed for maturation rates at $8 \mathrm{~h}$ intervals $(0,8,16$ and $24 \mathrm{~h} \mathrm{IVM})$.

\section{Experiment II: Effects of meiotic block on embryo development in vitro}

Oocytes ( $n=1640$ in 5 replicates) were cultured during $8 \mathrm{~h}$ with IBMX or roscovitine as previously mentioned in Experiment I and then were submitted to IVM for 16, 20 or $24 \mathrm{~h}$. As controls, a group of oocytes was only in vitro matured during $24 \mathrm{~h}$ without prior meiotic block. At the end of IVM culture, all oocytes were fertilized in vitro and cultured up to 8 days (D8). Cleavage, blastocyst development and hatching rates were recorded.

\section{Statistical analysis}

In this study, data were reported as mean \pm standard error (SEM). Data in percentages were arcsine transformed and analysed by ANOVA. When a statistical significant effect was found, multiple comparisons of means were determined using Tukey's test (SAS Program V.8). A p-value of less than 0.05 was considered to be statistically significant.

\section{Results}

\section{Experiment I}

In the first part of this experiment, most oocytes treated with IBMX and roscovitine with SR and hormones during $8 \mathrm{~h}$ culture remained in GV stage $(70.3 \pm 5.6 \%$ and $73.1 \pm 8.1 \%$ for IBMX and ROSC groups, 


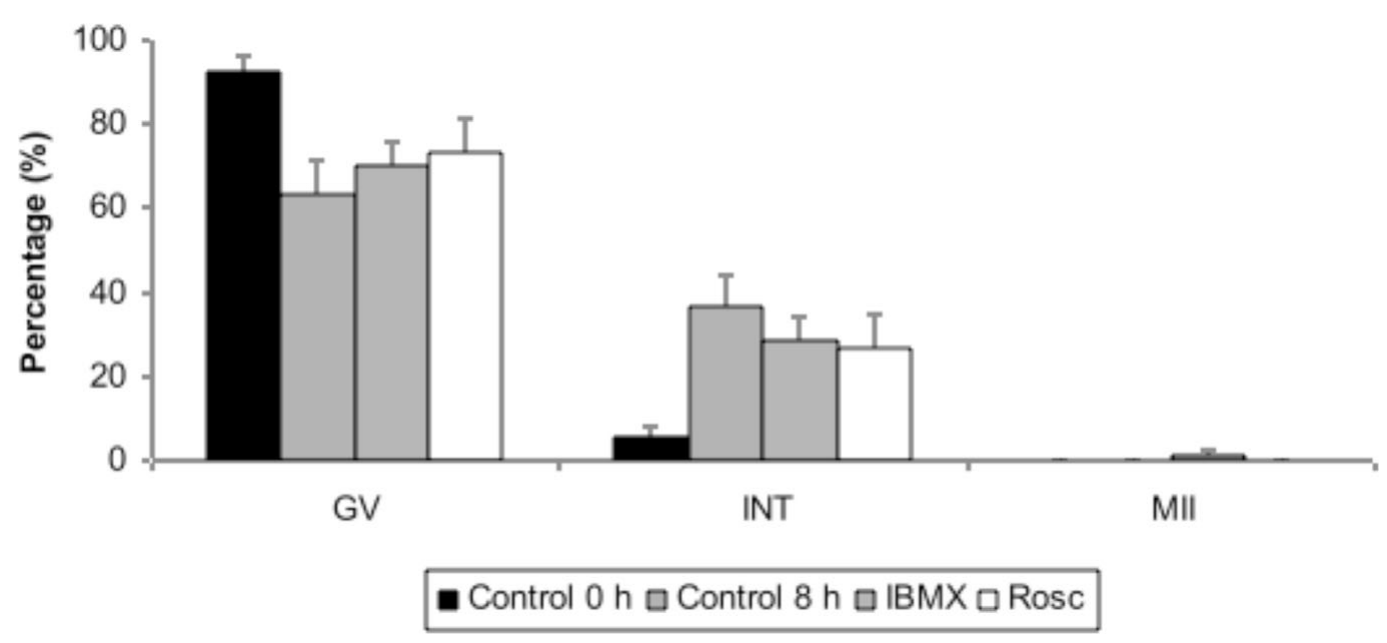

Figure 1 Meiotic status in bovine oocytes cultured for $8 \mathrm{~h}$ with IBMX or roscovitine in TCM-199 with Knockout SR ${ }^{\circledR}$ and hormones. Control $0 \mathrm{~h}$ : oocytes evaluated soon after follicle aspiration; Control $8 \mathrm{~h}$ : oocytes cultured in maturation medium (MM-TCM-199 with $10 \%$ Knockout, $0.5 \mu \mathrm{g} / \mathrm{ml} \mathrm{FSH,} 100 \mathrm{IU} / \mathrm{ml} \mathrm{hCG}$ and $1.0 \mu \mathrm{g} / \mathrm{ml}$ estradiol) for $8 \mathrm{~h}$ without meiotic inhibitors; IBMX: oocytes cultured in MM for $8 \mathrm{~h}$ with $0.5 \mathrm{mM} \mathrm{IBMX;} \mathrm{ROSC:} \mathrm{oocytes} \mathrm{cultured} \mathrm{in} \mathrm{MM} \mathrm{for} 8 \mathrm{~h}$ with $25 \mu \mathrm{M}$ roscovitine. GV: germinal vesicle; INT: intermediate stages of nuclear maturation, including metaphase I, anaphase I and telophase I; MII: metaphase II. ${ }^{\mathrm{a}, \mathrm{b}}$ Different letters indicate differences among treatments $(p<0.05)$.

respectively; $p>0.05$ ) (Fig. 1). The majority of control oocytes cultured for $8 \mathrm{~h}$ with SR and hormones but without meiotic inhibitors were also in GV (63.5 \pm $7.7 \%)$. Similarly, most control immature oocytes (Control $0 \mathrm{~h}$ ) evaluated soon after follicle aspiration were in GV stage $(92.5 \pm 3.9 \%)$. However, some oocytes progressed through meiosis and reached the intermediate stages of meiotic maturation (5.3-36.5\%; $p>0.05)$ and MII stage (0.0-1.4\%; $p>0.05 ;$ Fig. 1$)$.

After meiotic block for $8 \mathrm{~h}$, oocytes were IVM for $24 \mathrm{~h}$ in inhibitor-free media and oocytes were assessed for maturation rates at $8 \mathrm{~h}$ intervals. GV rates after $8 \mathrm{~h}$ IVM were greater $(p<0.05)$ for control oocytes $(63.5 \pm$ $7.7 \%)$ than for the treated ones (3.9-4.5\%), which were similar $(p>0.05)$ between themselves (Fig. 2). At this moment, most oocytes of IBMX $(82.5 \pm 5.5 \%)$ and ROSC $(92.1 \pm 0.8 \%)$ were in intermediate stages of meiosis $(p>0.05)$, but the controls had lesser rates $(36.5 \pm 7.7 \% ; p<0.05)$. A small proportion of oocytes in IBMX group (11.4 $\pm 3.2 \%)$ were in MII stage at $8 \mathrm{~h}$ IVM, but Control and ROSC had lesser rates $(0.0 \%$ and $3.7 \pm 0.7 \%$, respectively; $p<0.05$ ). At $16 \mathrm{~h}$, the rates of oocytes in the intermediate stages of meiosis were similar $(p>0.05)$ between treatments $(44.7-67.7 \%)$ (Fig. 2). On the other hand, a higher proportion $(p<$ $0.05)$ of oocytes of IBMX (53.8 $\pm 7.4 \%)$ and ROSC (55.3 $\pm 9.0 \%$ ) groups had reached MII stage when compared with Control $(15.6 \pm 3.5 \%)$. MII rates at $24 \mathrm{~h}$ IVM (Fig. 2) were similar $(p>0.05)$ between treatments (65.0-71.7\%).

When the meiotic block was conducted for $16 \mathrm{~h}$ (second part of this experiment), no oocytes remained in GV stage at similar rates to those recently aspirated $(p<0.05)$ (Fig. 3). GV rates in oocytes treated with ROSC $(32.4 \pm 6.9 \%)$ were higher $(p<0.05)$ than in Control $(8.6 \pm 6.2 \%)$, but similar $(p>0.05)$ to IBMX $(9.7 \pm 5.0 \%)$. In this experiment, the majority of oocytes progressed through meiosis, reaching the intermediate stages of meiotic maturation (67.6-86.9\%). Similar rates $(p>0.05)$ of oocytes reaching MII stage $(0.0-7.1 \%)$ were observed between treatments (Fig. 3).

Subsequently to the meiotic block for $16 \mathrm{~h}$, oocytes were IVM for $24 \mathrm{~h}$ in inhibitor-free media. At the beginning of culture $(0 \mathrm{~h}), \mathrm{GV}$ rates were greater $(p$ $<0.05)$ for Control $(79.9 \pm 8.3 \%)$ than for IBMX $(9.7$ $\pm 5.0 \%)$ and $\operatorname{ROSC}(32.4 \pm 6.7 \%)$, which were similar $(p>0.05)$ between themselves (Fig. 4). At this moment, the majority of IBMX $(83.2 \pm 5.9 \%)$ and ROSC $(67.6 \pm$ $6.9 \%)$ oocytes were in intermediate stages of meiosis $(p>0.05)$, which were greater $(p<0.05)$ than Control $(19.7 \pm 8.3 \%)$. After $8 \mathrm{~h}$ IVM, most oocytes of IBMX $(73.4 \pm 15.5 \%)$ and $\operatorname{ROSC}(65.4 \pm 5.6 \%)$ were in intermediate stages of meiosis $(p>0.05)$, but the controls had lesser rates (36.5 $\pm 7.7 \%$; $p<0.05$; Fig. 4). At this moment, some oocytes of IBMX $(26.6 \pm 15.5 \%)$ and ROSC $(31.4 \pm 4.7 \%)$ had reached MII $(p>0.05)$, while no control oocytes had reached this stage $(0.0 \%$; $p<0.05)$. At $16 \mathrm{~h}$, the majority control oocytes were in intermediate stages of meiosis $(86.9 \pm 5.6 \%)$, but $\operatorname{IBMX}(57.2 \pm 9.9 \%)$ and $\operatorname{ROSC}(41.9 \pm 3.2 \%)$ had lesser rates $(p<0.05)$ (Fig. 4). However, a higher proportion $(p<0.05)$ of oocytes of IBMX $(42.3 \pm 9.9 \%)$ and ROSC (57.2 $\pm 3.1 \%)$ groups had reached MII stage when compared with Control $(4.5 \pm 1.8 \%)$. MII rates at $24 \mathrm{~h}$ IVM (Fig. 4$)$ were similar $(p>0.05)$ between treatments $(45.9-60.4 \%)$. 

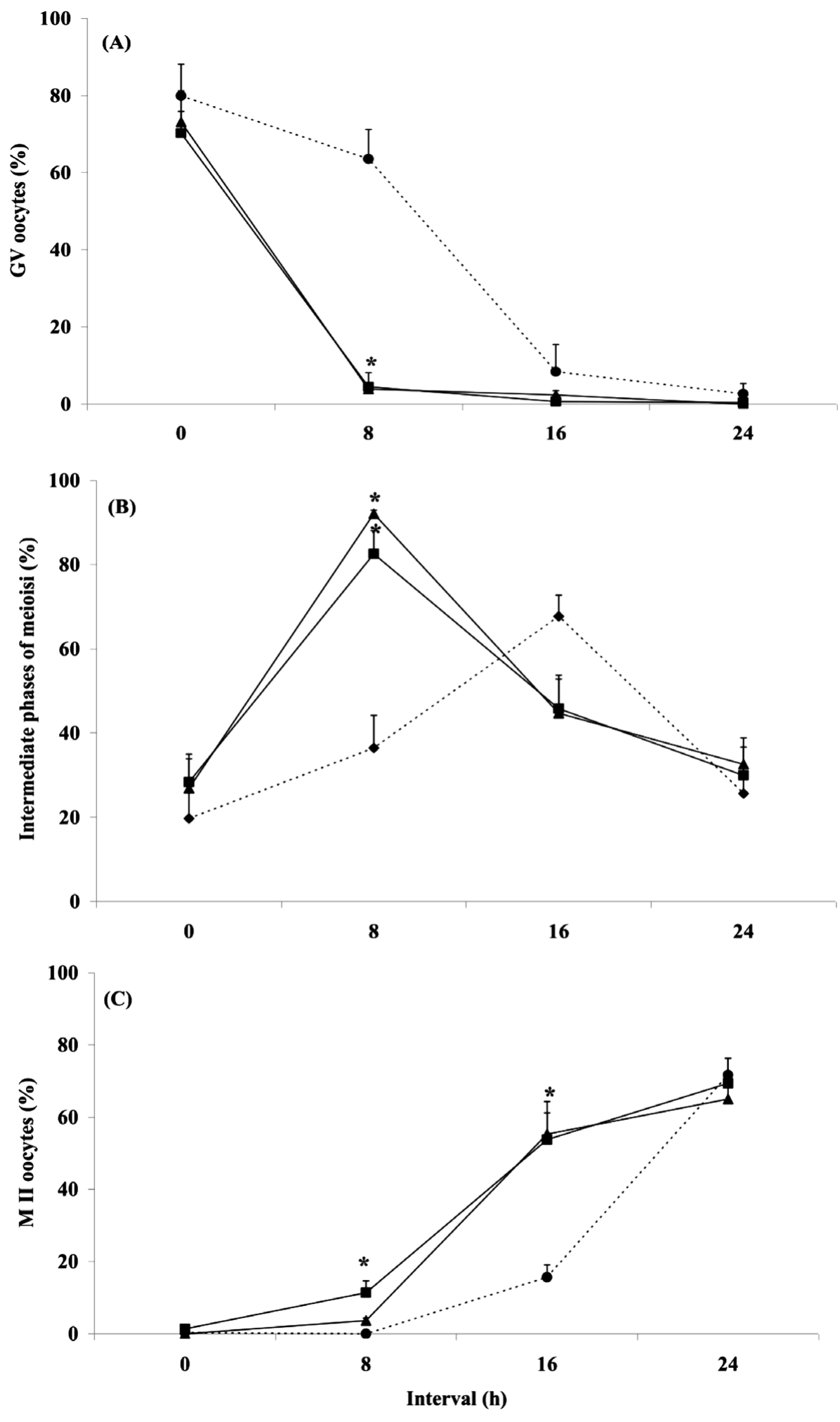

$\bullet$ Control $\rightarrow-$ IBMX $\rightarrow$ Roscovitine

Figure 2 Kinetics of oocyte maturation after $8 \mathrm{~h}, 16 \mathrm{~h}$ and $24 \mathrm{~h}$ IVM in bovine oocytes previously submitted to meiotic block for $8 \mathrm{~h}$ in TCM-199 with Knockout (10\%), hormones $(0.5 \mu \mathrm{g} / \mathrm{ml} \mathrm{FSH,} 100 \mathrm{IU} / \mathrm{ml} \mathrm{hCG}$ and $1.0 \mu \mathrm{g} / \mathrm{ml}$ estradiol) and meiotic inhibitors ( $0.5 \mathrm{mM}$ IBMX or $25 \mu \mathrm{M}$ roscovitine). (a) Percentage of germinal vesicle (GV) oocyte. (b) Percentage of oocytes in the intermediate stages of nuclear maturation, including metaphase I, anaphase I and telophase I. (c) Percentage of metaphase II (MII) oocytes. *Asterisk indicates difference from control within each time point $(p<0.05)$. 


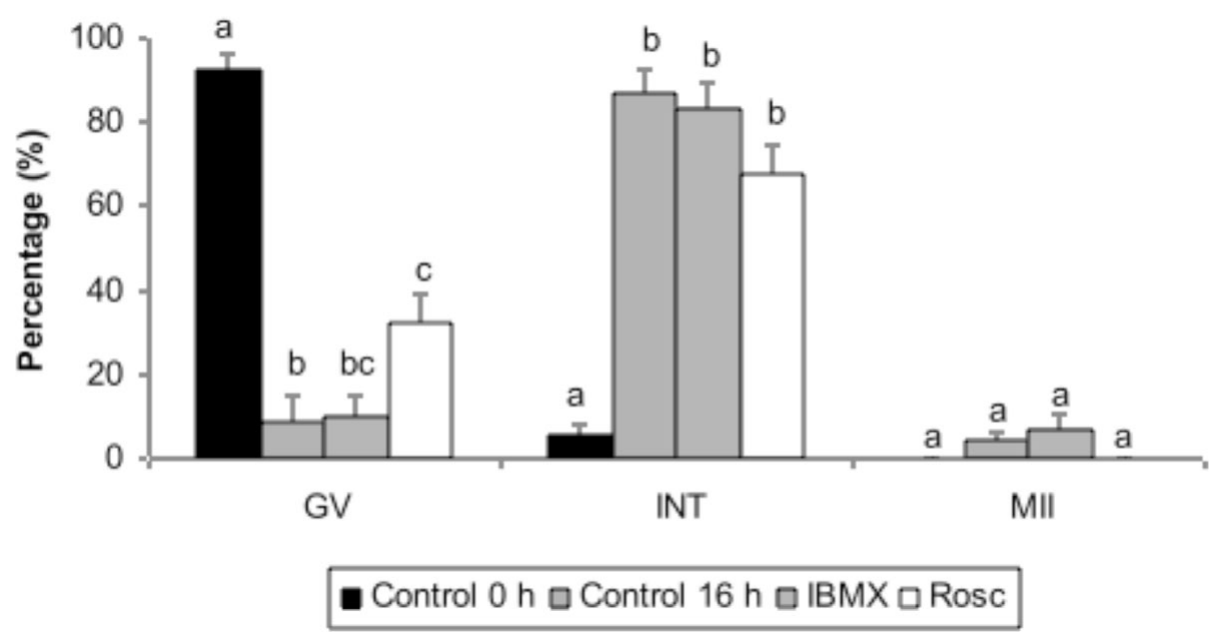

Figure 3 Meiotic status in bovine oocytes cultured for $16 \mathrm{~h}$ with IBMX or roscovitine in TCM-199 with Knockout and hormones. Control $0 \mathrm{~h}$ : oocytes evaluated soon after follicle aspiration; Control $16 \mathrm{~h}$ : oocytes cultured in maturation medium (MMTCM199 with $10 \%$ Knockout, $0.5 \mu \mathrm{g} / \mathrm{ml} \mathrm{FSH,} 100 \mathrm{IU} / \mathrm{ml} \mathrm{hCG}$ and $1.0 \mu \mathrm{g} / \mathrm{ml}$ estradiol) for 16 h without meiotic inhibitors; IBMX: oocytes cultured in MM for $16 \mathrm{~h}$ with $0.5 \mathrm{mM}$ IBMX; ROSC: oocytes cultured in MM for $16 \mathrm{~h}$ with $25 \mu \mathrm{M}$ roscovitine. GV: germinal vesicle; INT: intermediate stages of nuclear maturation, including metaphase I, anaphase I and telophase I; MII: metaphase II. ${ }^{\mathrm{a}, \mathrm{b}}$ Different letters indicate differences among treatments $(p<0.05)$.

\section{Experiment II}

To evaluate developmental competence of oocytes treated with IBMX and roscovitine in medium with SR and hormones during $8 \mathrm{~h}$, these oocytes were in vitro matured for 16, 20 or $24 \mathrm{~h}$, fertilized and cultured. Data for cleavage and embryonic development to blastocyst and hatched blastocyst are presented in Table 1 . Cleavage rates (67.8-78.2\%), embryonic development in D7 (25.0-35.6\%) and hatching rates in D8 (2.5-11.3\%) were similar for all groups $(p>0.05)$.

\section{Discussion}

Oocyte nuclear maturation together with the cytoplasmic maturation prepares oocytes for being fertilized and to acquire embryonic developmental competence (Thibault et al., 1987; Sirard et al., 1989). Currently, the effectiveness of in vitro culture systems used for embryo production (30-40\% blastocyst rate) is lower than that obtained in vivo (approximately 70\% blastocyst rate). Among several factors associated with culture systems that can explain such poor results, we can cite the short period that oocytes have to acquire developmental competence: $24 \mathrm{~h}$ of IVM culture. For comparison, in vivo, meiotically competent oocytes are maintained at the GV stage by the follicular environment until the preovulatory gonadotropin surge, which allow them to differentiate while included in a follicle as small as $2 \mathrm{~mm}$ (the size at which oocytes are punctured for IVM purposes: 2-8 mm) until ovulation (Marchal et al., 2001).
One way to offer the oocytes additional time for cytoplasmic maturation and developmental competence acquisition is to prematurate them in the presence of meiotic inhibitors, which could better induce the oocyte capacitation (Ponderato et al., 2001). However, several studies have recently demonstrated that prematuration of bovine oocytes in simple medium did not improve oocyte competence, but also did not cause major structural alterations in oocytes and embryos (Barretto et al., 2007; Adona et al., 2008). Then, it can be supposed that the addition of stimulatory components to the prematuration culture medium, such as hormones, could create a more suitable environment for promoting the developmental potential of the oocytes (Ponderato et al., 2002). For that reason, prematuration of bovine oocytes with meiotic inhibitors (IBMX and roscovitine) in medium supplemented with SR and hormones were used to assess their effects on meiotic block, meiosis progression after meiotic reversal and developmental competence.

$\mathrm{GV}$ rates after $8 \mathrm{~h}$ meiotic block (prematuration) were similar between groups, which did not differ from both the Control $8 \mathrm{~h}(8 \mathrm{~h}$ of IVM) and those evaluated soon after follicle aspiration (Control $0 \mathrm{~h}$ ). This finding was expected at this moment, since meiosis resumption in vitro is observed just after 6-8 h of IVM in inhibitor-free media (Sirard et al., 1989).

Nuclear maturation kinetics after meiotic block for $8 \mathrm{~h}$ was then followed. Meiotic resumption was accelerated similarly in both IBMX and ROSC treatments. At $8 \mathrm{~h}$ of IVM, most treated oocytes reached the intermediate phases of meiosis, while 

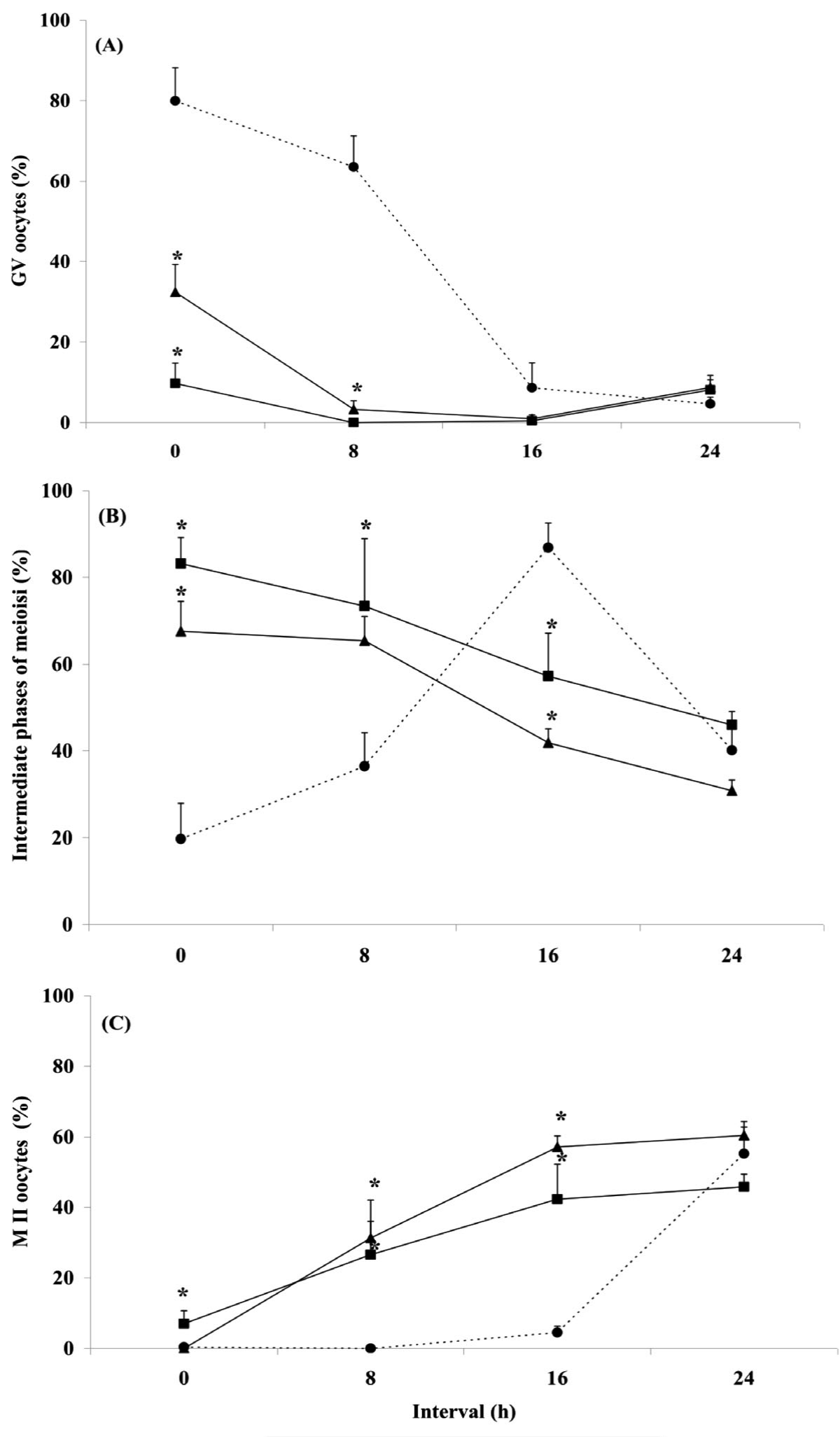

$\bullet \cdot$ Control $\rightarrow-$ IBMX $\_$Roscovitine

Figure 4 Kinetics of oocyte maturation after $8 \mathrm{~h}, 16 \mathrm{~h}$ and $24 \mathrm{~h}$ IVM in bovine oocytes previously submitted to meiotic block for $16 \mathrm{~h}$ in TCM-199 with Knockout (10\%), hormones $(0.5 \mu \mathrm{g} / \mathrm{ml} \mathrm{FSH,} 100 \mathrm{IU} / \mathrm{ml} \mathrm{hCG}$ and $1.0 \mu \mathrm{g} / \mathrm{ml}$ estradiol) and meiotic inhibitors (0.5 mM IBMX or $25 \mu \mathrm{M}$ roscovitine). (a) Percentage of germinal vesicle (GV) oocytes. (b) Percentage of oocytes in the intermediate stages of nuclear maturation, including metaphase I, anaphase I and telophase I. (c) Percentage of metaphase II (MII) oocytes. *Asterisk indicates difference from control within each time point $(p<0.05)$. 
Table 1 Embryo development of bovine oocytes previously submitted to meiotic block for $8 \mathrm{~h}$ in TCM-199 with Knockout SR ${ }^{\circledR}(10 \%)$, hormones $(0.5 \mu \mathrm{g} / \mathrm{ml} \mathrm{FSH,} 100 \mathrm{IU} / \mathrm{ml}$ hCG and $1.0 \mu \mathrm{g} / \mathrm{ml}$ estradiol) and meiotic inhibitors (0.5 mM IBMX or $25 \mu \mathrm{M}$ roscovitine).

\begin{tabular}{lccccc}
\hline \multirow{2}{*}{ Group } & & & \multicolumn{2}{c}{ Embryo development (mean \% \pm S.E.M.) } \\
\cline { 4 - 6 } & IVM (h) & Oocytes (n) & Cleavage & Blastocyst & Hatching \\
\hline Control & 24 & 237 & $182(76.6 \pm 4.0)^{a}$ & $67(29.6 \pm 6.6)^{a}$ & $17(7.1 \pm 3.1)^{a}$ \\
IBMX & 16 & 234 & $159(67.8 \pm 5.4)^{a}$ & $58(25.0 \pm 6.9)^{a}$ & $6(2.5 \pm 1.2)^{a}$ \\
Roscovitine & 16 & 234 & $173(73.8 \pm 8.7)^{a}$ & $76(35.2 \pm 6.8)^{a}$ & $13(5.7 \pm 1.4)^{a}$ \\
IBMX & 20 & 234 & $182(77.4 \pm 3.3)^{a}$ & $83(35.6 \pm 3.9)^{a}$ & $26(11.3 \pm 3.9)^{a}$ \\
Roscovitine & 20 & 235 & $185(78.2 \pm 3.3)^{a}$ & $74(31.7 \pm 2.0)^{a}$ & $19(8.5 \pm 2.8)^{a}$ \\
IBMX & 24 & 231 & $175(76.1 \pm 3.7)^{a}$ & $77(33.9 \pm 4.1)^{a}$ & $18(8.2 \pm 2.6)^{a}$ \\
Roscovitine & 24 & 235 & $184(78.0 \pm 4.1)^{a}$ & $77(33.0 \pm 4.7)^{a}$ & $19(8.4 \pm 3.0)^{a}$ \\
\hline
\end{tabular}

${ }^{a}$ Different letters within columns indicate significant differences $(p<0.05)$.

most control oocytes were still at GV stage. At $16 \mathrm{~h}$ of IVM, MII rates in treated oocytes were superior to control, indicating that the acceleration is mostly due to the premature meiotic resumption. These results may support the hypothesis that the activity of MPF and mitogen activated protein kinases (MAPK) are inhibited by roscovitine, but not their activation pathway (Marchal et al., 2001). According to these authors, roscovitine prevents MPF kinase activity by competing with ATP for binding cdk1 but does not prevent the formation of active MPF itself. Then, after roscovitine removal, active MPF is already present and could induce meiotic resumption more rapidly than in untreated oocytes deprived of active MPF. Besides CDK inhibitors, protein synthesis (Mayes \& Sirard, 2001) and phosphodiesterase inhibitors (Grupen et al., 2006), like IMBX, also accelerated meiotic resumption. Even short periods of meiotic block, as that used in the present study, cause such effects on nuclear maturation kinetics (Mayes \& Sirard, 2001).

To assess the effects of meiotic inhibitors in media supplemented with SR and hormones during more prolonged periods, oocytes were prematured for $16 \mathrm{~h}$. Nevertheless, IBMX could not maintain bovine oocytes at GV stage during $16 \mathrm{~h}$ in such culture system. Although GV rates in ROSC were higher than in Control $16 \mathrm{~h}$, the efficiency in blocking meiosis was reduced when compared with Control $0 \mathrm{~h}$ and to results of previous reported studies (Ponderato et al., 2001). The majority of oocytes (treated and control $16 \mathrm{~h}$ ) progressed meiosis until intermediate phases, as expected in a IVM culture free of meiotic inhibitors (10-18 h of IVM, according to Sirard et al., 1989).

Although adenylate cyclase activators and phosphodiesterase inhibitors, such as IBMX, had demonstrated to be capable of maintaining mouse oocytes at the GV stage (Eppig et al., 1996) and also assist growing oocytes to acquire GVBD competence (Chesnel et al., 1994), pharmacological elevation of intracellular CAMP in isolated COCs or denuded oocytes transiently delays spontaneous maturation in bovine oocytes (Schultz, 1991), maintaining the meiotic arrest for only approximately $3 \mathrm{~h}$ from GV (Lonergan et al., 1997). This transient effect is due to the interference of some substances present in the maturation media such as serum, hormones and growth factors (Harper \& Brackett, 1993), which act upon the adenylate cyclase pathway. For that reason, prematuration media were supplemented with Knockout $S R^{\circledR}$ in the present study, in order to avoid such undesirable effect. SR was developed for isolation and maintenance of embryonic stem cells (Goldsborough et al., 1998; Moore et al, 2007). The chemical formula of SR is protected by fabricant, but it is marketed as a defined serum-free supplement and is known to contain amino acids, glucose, insulin, transferring, antioxidants, inorganic salts, trace elements and a proprietary mix of proteins and vitamins. It does not contain growth factors, cytokines, hormones, immunoglobulins or the macromolecules PVA or PVP.

Unfortunately, replacement of serum by SR could not maintain meiosis blocked for periods as long as $16 \mathrm{~h}$, but it remains to be investigated if this undesirable effect was due to some interaction of meiotic inhibitors with SR and/or the hormones present in prematuration media.

Effective meiotic blockage has already been obtained using drugs that affect MPF activity, like roscovitine (Ponderato et al., 2001). On the contrary, our data demonstrated that roscovitine was unable to block meiosis for periods as long as $16 \mathrm{~h}$ when prematuration media was supplemented with SR and hormones. Based in the present results, we can suppose that SR and/or the stimulatory components (hormones) added to the prematuration media have negatively affected the effect of both meiotic inhibitors used in this study (IBMX and roscovitine).

Nuclear maturation kinetics after meiotic block for $16 \mathrm{~h}$ was evaluated and it was observed acceleration 
in meiotic progression during IVM. As previously discussed, these results may be a consequence of the premature meiotic resumption, mainly in this specific experiment where most treated oocytes were at intermediate stages of meiosis in the beginning of IVM culture.

In summary, we observed that oocyte prematuration with meiotic inhibitors supplemented with SR and hormones was not efficient in maintaining meiotic block for periods longer than $8 \mathrm{~h}$, however, this culture system did not compromise subsequent progression to MII. Moreover, previous results from our laboratory have demonstrated that prematuration of bovine oocytes in similar culture conditions did not impair oocyte cytoplasmic maturation, assessed by the analysis of CG repositioning (Barretto et al., 2007). Then, acquisition of developmental competence was assessed. Oocytes were prematured for $8 \mathrm{~h}$ and then submitted to IVM (for 16, 20 and $24 \mathrm{~h}$; to test the best moment for fertilization, due to the meiosis acceleration after prematuration culture), IVF and IVC. Independently of treatment and IVM duration, the results obtained for cleavage (67.8-78.2\%) and development to blastocyst (25.0-35.6\%) and hatched blastocyst $(2.5-8.5 \%)$ were similar to the average results described in the literature and even superior to results of Moore et al. (2007) who have obtained 16.5\% of blastocyst rate after IVM with SR. Then, present results indicate that both replacement of serum by SR during IVM of bovine oocytes and prematuration with meiotic inhibitors with SR and hormones had no adverse effect on embryo development.

It is well known that embryo development depends on the quality of nuclear and cytoplasmic maturation. Some studies (Ponderato et al., 2002; Shimada et al., 2003) suggested that mammalian oocytes can respond to the manipulation of factors applied during meiotic arrest that can increase oocyte developmental competence. Shimada et al. (2003) demonstrated that induction of $\mathrm{LH}$ receptors by exposure of porcine COC to $\mathrm{FSH}$ during induced meiotic arrest with IBMX resulted in an increase in developmental competence.

Regarding roscovitine, it is supposed that its inhibitory effect on MPF activity may also interfere with cytoplasmic maturation, since MPF also modulates the properties of proteins included in the regulation of cytoskeletal organization (Parrish et al., 1992). In fact, a recent work (Adona et al., 2008) has demonstrated that butyrolactone, a cdk inhibitor that selectively inhibits MPF like roscovitine does, reversibly blocked CG migration and partially blocked mitochondria translocation, demonstrating that MPF and/or MAPK can be implicated in organelle movement control. However, other studies (Vigneron et al., 2004) suggested that cytoplasmic maturation is not completely blocked during meiotic block and that other factors besides
MPF could participate in this control. Then, based in the knowledge that CG migration and mitochondrial aggregation during porcine oocyte maturation showed a dose-dependant relationship with gonadotropin concentrations (Sha et al., 2009), we tried to improve cytoplasmic maturation and, consequently, developmental competence during meiotic block by adding hormones to the prematuration culture. However, in the present work, gonadotropins did not improve developmental competence during meiotic block of bovine oocytes and even have negatively affected the meiotic block itself. Then, the results suggest that stimulatory substances, like gonadotropins and estradiol were not suitable supplements for meiotic block culture.

To conclude, this research has demonstrated that addition of Knockout SR ${ }^{\circledR}$ and hormones to meiotic block culture with IBMX and roscovitine negatively affected meiotic arrest, but did not impair oocyte nuclear maturation and acquisition of developmental competence.

\section{Acknowledgements}

This work was supported by the Fundação de Amparo a Pesquisa do Estado de São Paulo (FAPESP), Brazil, Grant \#01/06137-0. V.S.D. Caiado Castro was recipient of studentship from CAPES, Brazil and L.S.S. Barretto was recipient of studentship from FAPESP, Brazil.

\section{References}

Adona, P.R., Pires, P.R., Quetglas, M.D., Schwarz, K.R. \& Leal, C.L. (2008). Prematuration of bovine oocytes with butyrolactone I: effects on meiosis progression, cytoskeleton, organelle distribution and embryo development. Anim. Reprod. Sci. 108, 49-65.

Avery, B., Hay-Schmidt, A., Hyttel, P. \& Greve, T. (1998). Embryo development, oocyte morphology and kinetics of meiotic maturation in bovine oocytes exposed to 6dimethylaminopurine prior to in vitro maturation. Mol. Reprod. Dev. 50, 334-44.

Barretto, L.S., Caiado Castro, V.S., Garcia, J.M. \& Mingoti, G.Z. (2007). Role of roscovitine and IBMX on kinetics of nuclear and cytoplasmic maturation of bovine oocytes in vitro. Anim. Reprod. Sci. 99, 202-07.

Chesnel, F., Wigglesworth, K. \& Eppig, J.J. (1994). Acquisition of meiotic competence by denuded mouse oocytes: participation of somatic-cell product(s) and cAMP. Dev. Biol. 161, 285-95.

Eppig, J.J., O'Brien, M. \& Wiggleworth, K. (1996). Mammalian oocyte growth and development in vitro. Mol. Reprod. Dev. 44, 260-78.

Goldsborough, M.D., Tilkins, M.L., Price, P.J., Lobo-Alfonso, J., Morrison, J.R., Stevens, M.E., Meneses, J., Pedersen, R., Koller, B. \& Latour, A. (1998). Serum-free culture of murine embryonic stem (ES) cells. Focus 20, 8-11. 
Gosden, R., Krapez, J. \& Briggs, D. (1997). Growth and development of the mammalian oocyte. Bioessays 10, 87582.

Grupen, C.G., Fung, M. \& Armstrong, D.T. (2006). Effects of milrinone and butyrolactone-I on porcine oocyte meiotic progression and developmental competence. Reprod. Fertil. Dev. 18, 309-17.

Harper, K.M. \& Brackett, B.G. (1993). Bovine blastocyst development after in vitro maturation in a defined media with epidermal growth factor and low concentrations of gonadotropins. Biol. Reprod. 48, 409-16.

Hyttel, P., Fair, T., Callesen, H. \& Greve, T. (1997). Oocyte growth, capacitation and final maturation in cattle. Theriogenology 47, 28-32.

Lohmann, S.M. \& Walter, U.W. (1984). Regulation of the cellular and subcellular concentrations and distribution of cyclic nucleotide-dependent protein kinase. In Advances in Cyclic Nucleotide and Protein Phosphorylation Research, (ed. Greengard, P.), pp. 63-115. New York: Raven Press.

Lonergan, P., Khatir, H., Carolan, C. \& Mermillod, P. (1997). Bovine blastocyst production in vitro after inhibition of oocyte meiotic resumption for 24 h. J. Reprod. Fertil. 109, 355-65.

Mayes, M.A. \& Sirard, M.A. (2001). The influence of cumulus-oocyte complex morphology and meiotic inhibitors on the kinetics of nuclear maturation in cattle. Theriogenology 55, 911-22.

Marchal, R., Tomanek, M., Terqui, M. \& Mermillod, P. (2001). Effects of cell cycle dependent kinases inhibitor on nuclear amd cytoplasmic maturation of porcine oocytes. Mol. Reprod. Dev. 60, 65-73.

Mermillod, P., Tomanek, M., Marchal, R. \& Meijer, L. (2000). High developmental competence of cattle oocytes maintained at the germinal vesicle stage for 24 hours in culture by specific inhibition of MPF kinase activity. Mol. Reprod. Dev. 55, 89-95.

Moore, K., Rodriguez-Sallaberry, C.J., Kramer, J.M., Johnson, S., Wroclawska, E., Goicoa, S. \& NiasariNaslaji, A. (2007). In vitro production of bovine embryos in medium supplemented with a serum replacer: effects on blastocyst development, cryotolerance and survival to term. Theriogenology 68, 1316-25.

Parrish, J.J., Kim, C.I. \& Bae, I.H. (1992). Current concepts of cell-cycle regulation and its relationship to oocyte maturation, fertilization and embryo development. Theriogenology 38, 277-96.

Ponderato, N., Lagutina, I., Crotti, G., Turini, P., Galli, C. \& Lazzari, G. (2001). Bovine oocytes treated prior to in vitro maturation with a combination of butyrolactone I and roscovitine at low doses maintain a normal development capacity. Mol. Reprod. Dev. 60, 579-85.

Ponderato, N., Crotti, G., Turini, P., Duchi, R., Galli, C. \& Lazzari, G. (2002). Embryonic and foetal development of bovine oocytes treated with a combination of butyrolactone I and roscovitine in an enriched medium prior to IVM and IVF. Mol. Reprod. Dev. 62, 513-18.

Rizos, D., Ward, F., Duffy, P., Boland, M.P. \& Lonergan, P. (2002). Consequences of bovine oocyte maturation, fertilization on early embryo development in vitro versus in vivo: implications for blastocyst yield and blastocyst quality. Mol. Reprod. Dev. 61, 234-48.

Rodriguez, K.F. \& Farin, C.E. (2004). Developmental capacity of bovine cumulus oocytes complexes after transcriptional inhibition of germinal vesicle breakdown. Theriogenology 61, 1499-511.

Schultz, R.M. (1991). Meiotic maturation of mammalian oocytes. In Elements of Mammalian Fertilization, (ed. Wasserman, P.M.), pp. 77-104. Boca Raton: FL, CRC Press.

Shimada, M., Nishibori, M., Isobe, N., Kawano, N. \& Terada, T. (2003). Luteinizing hormone receptor formation in cumulus cells surrounding porcine oocytes and its role during meiotic maturation of porcine oocytes. Biol. Reprod. 68, 1142-49.

Sirard, M.A., Florman, H.M., Leibfried-Rutledge, M.L., Barnes, F.L., Sims, M.L. \& First, N.L. (1989). Timing of nuclear progression and protein synthesis necessary for meiotic maturation of bovine oocytes. Biol. Reprod. 40, 1257-63.

Sha, W., Xu, B.Z., Li, M., Liu, D., Feng, H.L. \& Sun, Q.Y. (2009). Effect of gonadotropins on oocyte maturation in vitro: an animal model. Fertil. Steril. (In press doi: 10.1016/j.fertnstert.2009.03.003).

Thibault, C., Szöllösi, D. \& Gérard, M. (1987). Mammalian oocyte maturation. Reprod. Nutr. Dev. 27, 865-96.

Tsafriri, A., Chun, S.Y., Zhang, R., Hsueh, A.J. \& Conti, M. (1996). Oocyte maturation involves compartmentalization and opposing changes of cAMP levels in follicular somatic and germ cells: Studies using selective phosphodiesterase inhibitors. Dev. Biol. 178, 393-402.

Vigneron, C., Perreau, C., Dupont, J., Uzbekova, S., Prigent, C. \& Mermillod, P. (2004). Several signaling pathways are involved in the control of cattle oocyte maturation. Mol Reprod Dev. 69, 466-74.

Yang, X., Kubota, C., Suzuki, H., Taneja, M., Bols, P.E. \& Presicce, G.A. (1998). Control of oocyte maturation in cows-biological factors. Theriogenology 49, 471-82. 